\title{
Phenotypic Characterization, Genetic Analysis and Molecular Mapping of a New Floral Organ Mutant Gene in Rice
}

\author{
Jing Zhang1,2, Shuangcheng $\mathrm{Li}^{2}$, Ping $\mathrm{Li}^{2 *}$ \\ ${ }^{1}$ Technical Center of Inspection and Quarantine, Sichuan Enter-Exit Inspection and Quarantine Bureau, \\ Chengdu, China \\ ${ }^{2}$ Rice Research Institute, Sichuan Agricultural University, Wenjiang, China \\ Email: jingzhang927@gmail.com, lisc0750@sina.com, "liping6575@163.com
}

Received 7 November 2015; accepted 29 November 2015; published 2 December 2015

Copyright (C) 2015 by authors and Scientific Research Publishing Inc.

This work is licensed under the Creative Commons Attribution International License (CC BY).

http://creativecommons.org/licenses/by/4.0/

cc) (i) Open Access

\section{Abstract}

A rice floral organ mutant, srs2, derived from a spontaneous mutation, was first discovered in a japonica rice variety GNZ. The mutant displayed various abnormalities in floral organ including longer paleas/lemmas, split spikelets, palea/lemma-like lodicules, two florets of the same rachilla, a decrease in stamen number, and an increase in pistil number. Moreover, the seed-setting rate of the mutant was also reduced to $9.8 \%$. Observations of the floral organ morphogenesis by a scanning electron microscope (SEM) in the mutant indicated that the development of androecium and gynoecia was abnormal and an additional floret and several palea/lemma-like lodicules were usually formed by the irregular development of the floral meristem. Genetic analysis of $4 F_{2}$ and 2 $\mathrm{BC}_{1} \mathrm{~F}_{1}$ populations showed that the mutation was controlled by a single recessive gene, and designated as srs 2 (spit rice spikelet 2). Screening of $643 \mathrm{~F}_{2}$ mutant individuals derived from the cross of $s r s 2 \times 202 R$ with simple sequence repeat (SSR) markers demonstrated that SRS2 is located between the molecular marker S31 and L75, at a distances of 0.07 and $2 \mathrm{cM}$, respectively, on chromosome 3. The SRS2 gene was also discussed to be a new floral organ identity gene in rice.

\section{Keywords}

Rice, Floral Organ, Mutant, Mapping

\section{Introduction}

Floral organ development plays an important role in the transition of vegetative to reproductive phase, and is di-

\footnotetext{
${ }^{*}$ Corresponding author.
}

How to cite this paper: Zhang, J., Li, S.C. and Li, P. (2015) Phenotypic Characterization, Genetic Analysis and Molecular Mapping of a New Floral Organ Mutant Gene in Rice. American Journal of Plant Sciences, 6, 2973-2983. 
rectly correlated with the yield and quality in angiosperm plant. Consequently, many genetic and molecular studies have focused on the floral development process and have already made great achievements. Based on the works carried on two model eudicots, Arabidopsis thaliana (Arabidopsis) and Antirrhinum majus (snapdragon), an "ABC" model was established for the determination of floral organ identities [1] and was widely accepted. This model proposes that each class of floral homeotic genes-termed A, B and C, encodes proteins with a very conserved MADS box motif-works in a single or two adjacent whorls among the four whirls of dicot flowers and regulates the floral organ pattern formation. Subsequently, the classical "ABC" model has been extended to the "ABCDE" model to better understand the determination of ovule development [2]-[6].

Rice is not only one of the most important food crops in the world, but also an ideal model monocot plant for genetics and molecular biology. On account of the fact that the seed is the main organ for harvesting, floral organ development is especially vital for rice yield. Moreover, rice floral organ mutants are useful tools for isolating genes involving floral organ development. At present, some rice mutants that display abnormalities in spike development have been reported, such as SRS [7], srg [8], ah [9], pall [10], spw1 [11], fzp [12], lh [13], $m g$ [14], and lhs1 [15]. It is still uncertain whether the model for dicot floral development works in a monocot plant. However, a lot of floral organ identity genes have been successfully isolated by homologous clone, transgenic experiment and floral mutant analysis in rice. An increasing body of research suggests that the "ABC" model also works in a monocot plant, even though the monocot floral structures were different from the dicot. Among them, RAP1A and RAP1B belong to class A [16] [17], OsMADS2, OsMADS4 and OsMADS16 [11] [18] belong to class B; RAG and OsMADS3 [19] belong to class C, MADS13 [20] belongs to class D and OsMADS1, OsMADS24 and OsMADS45 belongs to class E [21] [22]. With more and more rice floral controlling genes being isolated and functionally elucidated, some molecular mechanisms of floral organ identity in rice are becoming evident. However, the molecular basis for most of the developmental process still remains unknown. We report herein the phenotypic characterization, genetic analysis and molecular mapping of a new floral rice mutant derived from a spontaneous mutation. It would be a foundation for further gene cloning and understanding of the molecular mechanism underlying rice floral organ identity.

\section{Materials and Methods}

\subsection{Plant Materials}

The mutant material srs2 was derived from a spontaneous mutation of the japonica rice variety GNZ, other wild-type rice lines such as 202R, G630, M63 and 9311 were also used for phenotypic characterization or construction of segregated populations. All materials were offered by Rice Research Institute of Sichuan Agricultural University.

\subsection{Anatomic and Paraffin Section}

Floral structures of the mutant and wild-type plant were observed under an optical microscope before flowering. Pollen fertility was investigated after staining with 1\% I2-KI solution [23]. Anthers of the florets were placed on slides with I2-KI solution and nipped into pieces with forceps to spill out pollen grains. Then, pollen fertility was estimated according to its morphology and its staining gradation under a microscope [24] [25].

Paraffin sections were prepared using the method of Li et al. [25] with some modifications. Spikelets at various developmental stages were collected and fixed in FAA (5\% formaldehyde, $5 \%$ acetic acid, and $45 \%$ ethanol) for approximately $24 \mathrm{~h}$ at $4{ }^{\circ} \mathrm{C}$. Spikelets were washed in low concentration ethanol (10\%) and stained in $10 \%$ hematoxylin solution for $24-48 \mathrm{~h}$. The stained samples were dehydrated in a series of liquid ethanol degradations from $30 \%$ to $100 \%$, incubated in dimethylbenzene twice, dipped in paraffin for 7 days, and subsequently embedded in new paraffin. The paraffin was sectioned into pieces with $8 \mu \mathrm{m}$ in thickness. The perfect slides were deparaffinized in xylene and sealed by Canadian Resin. The images were taken under Olympus light microscopes BH-2.

\subsection{Scanning Electron Microscopy (SEM)}

Scanning electron microscopy was performed according to Feng [26] and Mizukami et al. [27] with some modifications. Young panicles at the floral organ differentiation stage were fixed in $3 \%$ glutaraldehyde solution for $24 \mathrm{~h}$ at $4^{\circ} \mathrm{C}$, dehydrated in a series of liquid ethanol degradations (25\%,50\%, 70\% and 100\%), and incubated in 
ethanol-isoamyl acetate mixture for $1 \mathrm{~h}$. The samples were then dried and coated with gold powder. The goldcoated specimens were finally examined and photographed with SEM (JSM-35CF, JEOL, Japan) at an acceleration voltage of $25 \mathrm{kV}$.

\subsection{Genetic Analysis of the Mutation}

Srs2, using as female parent, was crossed with G630, M63, 9311, 202R and 527R, respectively, in Wenjiang, Sichuan province, China, in the summer of 2004. In the winter of the same year, the $\mathrm{F}_{1}$ plants were then self-crossed or backcrossed with the mutant to generate $\mathrm{F}_{2}$ or $\mathrm{BC}_{1} \mathrm{~F}_{1}$ populations in Linshui, Hainan province, China. In 2005, all the segregated populations were planted in Wenjiang, Sichuan province, China. After flowering, all individuals in the segregated populations were subjected to flora organ investigations and the ratios of mutant versus normal individual were recorded for genetic analysis.

\subsection{DNA Extraction and PCR (Polymerase Chain Reaction) Screening}

The total rice genomic DNA was isolated according to the method of Wang and Fang [28] and Zuo et al. [23] with modifications. Powdered rice leaves were first incubated with the extraction buffer (100 mM Tris-Cl; 50 mM EDTA; $500 \mathrm{mM} \mathrm{NaCl} ; 1.5 \%$ SDS; $\mathrm{pH} 8.0$ ) at $65^{\circ} \mathrm{C}$, and then phenol-chloroform extraction and alcohol precipitation were performed.

PCRs were performed in a final mix of $20 \mu \mathrm{L}$ containing 50 ng template DNA, $2 \mu \mathrm{L} 10 \times$ reaction buffer (with $1.5 \mathrm{mM} \mathrm{Mg}^{2+}$ ), $0.2 \mathrm{mM}$ dNTP mixture, $0.2 \mu \mathrm{M}$ of each primer, and 1 unit of Taq DNA polymerase. The thermal profile was as follows: $94^{\circ} \mathrm{C}$ for $5 \mathrm{~min}, 35$ cycles of $94^{\circ} \mathrm{C}$ for $45 \mathrm{sec}, 55^{\circ} \mathrm{C}$ for $45 \mathrm{sec}$, and $72^{\circ} \mathrm{C}$ for $1 \mathrm{~min}$, and a final extension at $72^{\circ} \mathrm{C}$ for $7 \mathrm{~min}$. PCR products were separated on $3 \%$ agarose gels.

\subsection{Molecular Mapping of the Mutant Gene}

All the parents were screened with 512 pairs of SSR primers (sequences were released by GRAMENE, http://www.gramene.org/microsat/ssr.html, and synthesized by Shanghai biotechnology Co. Ltd.). The most polymorphic population was selected for gene mapping. The polymorphic markers in the two parents were first analyzed in a small population including the 2 parents, 4 of the $F_{2}$ wild-type plants, and 6 of the $F_{2}$ mutants. Then markers selected from the small population were further utilized to screen the total of 643 mutant individuals in the same segregated population for linkage analysis. Subsequently, several publicly available SSR markers in rice genome, located in the neighborhood of the linked marker, were obtained from GRAMENE (http://www.gramene.org/microsat/ssr.html) and surveyed with the same method to get the detailed mapping information. To fine-map the locus for the mutation, based on the known rice genomic sequences provided by the TIGR (http://rice.plantbiology.msu.edu/), new SSRs, InDels, and CAPS markers were developed [29]. Data were collected and transformed according to the requirement of MAP MARKER 3.0 software [30], by which the linkage map was constructed.

\section{Results}

\subsection{Morphology of the Mutant}

No obvious differences were observed between the mutant and the wild type rice before heading time. The difference appeared intuitively (Figure 1(A)) after heading time. Compared with the wild type rice (Figure 1(B) and Figure 1(E)), the mutant showed that the palea and lemma was longer, the top of the palea/lemma was split and erected, and the pistils and stamens were abnormal both in the number and in the appearance (Figure 1(C)). Moreover, several palea/lemma-like organs between palea and lemma and one or two florets from the same rachilla were observed in the mutant (Figure $1(\mathrm{~F})$ ). After flowering the palea and lemma were desiccated gradually and the palea/lemma-like organs finally became needle-like structures. The seed-setting rates of the mutant decreased to $9.8 \%$ and approximately 3.5\% of the flowers generated twin-seeds (Figure $1(\mathrm{G})$ ). Given that a rice floral organ mutant SRS (spit rice spikelet) was reported previously with similar phenotypes to the present one [7], we named it srs2.

Anatomical observations of the mutant revealed that about $60 \%$ of the spikelets had two incomplete florets. The lodicules were transformed into palea-like and lemma-like structures and acted as partitions of the two in- 


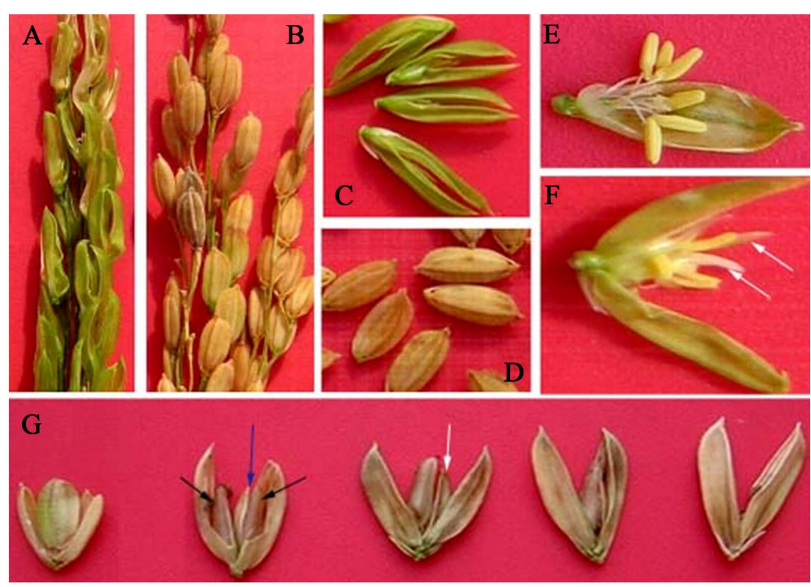

Figure 1. Phenotype of the srs2 mutant. (A) Spike of the srs2 mutant; (B) Spike of the wild type rice; (C) The paleas and lemmas are overdeveloped and the spikelets are open; (D) Grains of wild type rice; (E) A flower of wild type; (F) A flower of the srs2 mutant, indicating the double flowers setting and the palea and lemma-like structure(arrowhead); $(G)$ Seeds setting of the wild type(left) and mutant (right) (arrowhead).

complete florets (Figure 2(B)). The number of palea-like and lemma-like structures ranged from 2 to 4 . A mutant floret always has 3 - 4 stamens, one or more pistils and 2 - 3 stigmas (Figure 2(C)). Besides, great increased pistils were found in some florets and in the most serious mutant floret nothing were observed except a tuft of clamped pistils. Some spikelets had only one incomplete floret (Figure 2(A)), accompanied by 1 - 2 palea/lemma-like organs and calus-like structures, which were believed to be the undeveloped floral tissue (Figure 2(D)). Approximately $40 \%$ of the spikelets had one incomplete floret and several palea and lemma-like organs. In the single floret mutant, stamens-transformed palea/lemma-like organs, lodicule-transformed stamens, together with some transparent nubbles were also observed (Figure 2(E) and Figure 2(F)). However, no normal florets were found in the mutant though 500 samples were investigated (Figure 2(H)). Paraffin sections of mature florets of the mutant and the wild type rice were observed under an optical microscope, and the results were consistent with the anatomical observation (Figure 3).

Through $\mathrm{I}_{2}$-KI staining and microscopic observation, we found that the pollen grains in the mutant were apparently less than that in wild type rice, and the staining gradation in the mutant was pale (Figure 4(A)), while in the wild type rice (Figure 4(B)), the overwhelming majority of the pollen grains were deep stained. According to the morphology and the staining gradation, the pollen fertility of the mutant was estimated to lower than $20 \%$, while that in the wild type was approximately $92.3 \%$. It was proposed that the low seed setting rate of the mutant was attributed to the combinatorial activities of the low pollen fertility, the abnormal development of pistils, the decrease in stamen number, and the water loss of female organs caused by the opened spikelets.

\subsection{Floral Organ Morphogenesis}

The process of floral organ morphogenesis was investigated under a scanning electron microscope (SEM). At the early period of the flower development, the floral primordium of mutant developed irregularly (Figure 5(D)), while the floral primordium of wild type appeared spheroidal (Figure 5(A)). At the stage of stamen and pistil primordium differentiation, the mutant differs from one or two florets which were finally generated from the same rachilla. At the beginning of stamen differentiation, five stamen primordia of the wild type were formed synchronous, while the development of the stamen closed to the lemma was slightly tardier. (Figure 5(B)). In the one-floret type mutant flower, the stamen primordium was not observed and the whole floral primordium developed irregularly to form a triangle structure (Figure 5(E)). While in the two-floret type mutant flower, one half of the floret primordium (Figure 5(J)) shrinked from one side (Figure 5(K)) and formed a spindle-shaped structure (Figure 5(L)). At the middle stage of stamen and pistil primordium differentiation, the stamens primordial were distributed evenly around the carpel in the wild type rice (Figure 5(C)). In the one-floret type mutant flower at this stage, stamen primordium and carpel were formed irregularly (Figure 5(F)), and several 

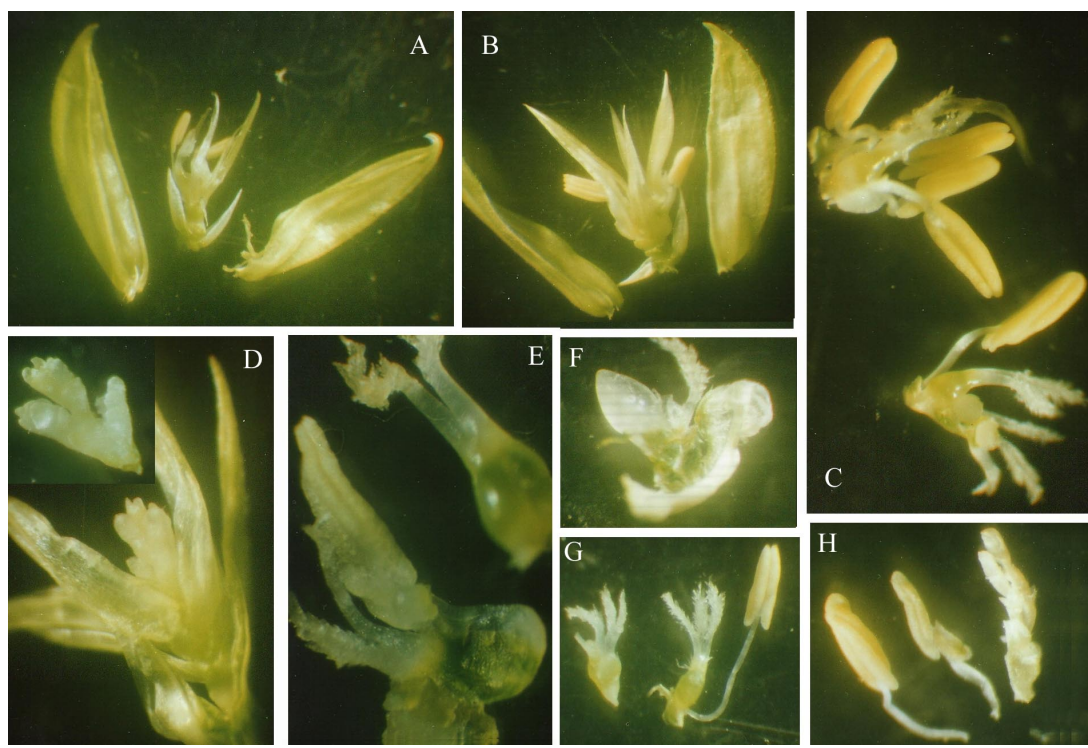

Figure 2. Anatomic observations of the srs2 mutant floret. (A) One incomplete floret and several palea and lemma-like structures in the bract; (B) Two incomplete florets and several palea and lemma-like structures in the bract; (C) The two florets were both abnormal with much pistils and less stamens; (D) Calus-like structures in series of palea and lemma-like structures; (E) Stigma and stamen-like organ generated from lodicule; F, bulged tissues on the lodicule; $(G)$ Tufty ovaries in a floret were seperated; (H) A normal anther, an anther-like lodicule, and calus-like tissues in the position of anthers.

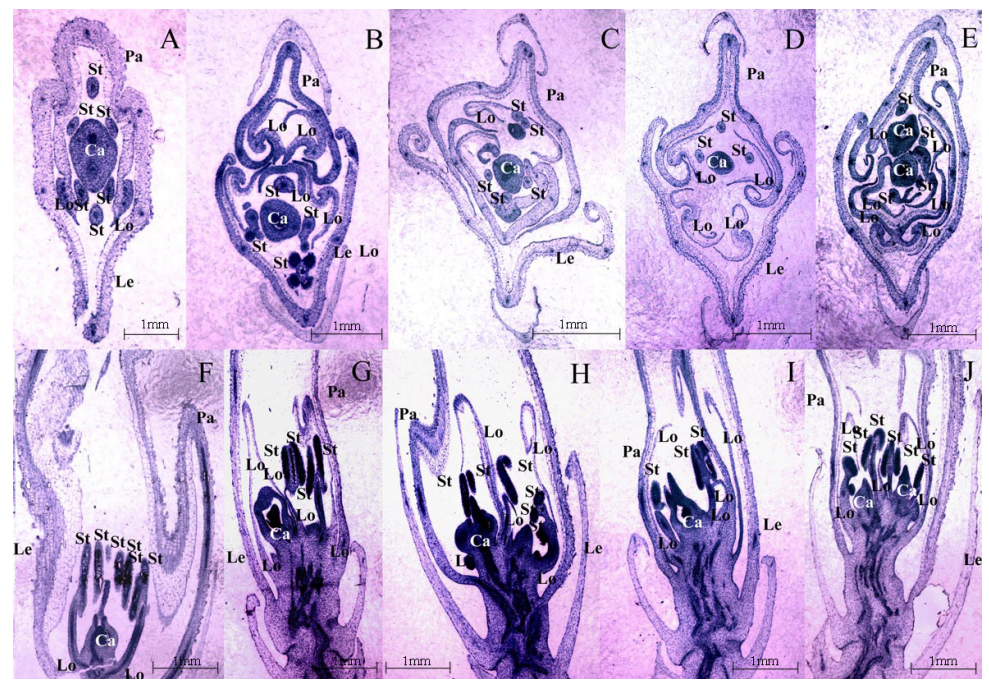

Figure 3. Section of srs2 mutant spikelet. (A) Cross-sectioned wild-type spikelet. The wild-type spikelet has glumes, palea and lemma, a pair of lodicules, six stamens, and a pistil; (B)-(E): A crosssectioned srs2 mutant spikelet. (B) The spikelet has one incomplete floret which consists of one pistil and four stamens and series of palea and lemma-like structures; (C) The spikelet has one incomplete floret consists of one pistil and five stamens, several palea and lemma-like structures and a calus-like structure (arrowhead); (D) The spikelet has one pistil, three stamens and four abnormal lodicules; (E) The spikelet has two florets, a pair of palea and lemma-like structures and three lodicules. Each floret consists of one pstil and two incomplete stamens; (F) Longitudinal-sectioned wild-type spikelet. The wild-type spikelet has glumes, palea and lemma, a pair of lodicules, six stamens, and a pistil; (G)-(J) Longitudinal-sectioned srs2 mutant spikelet; $(G)$ The spikelet has two incomplete florets and several palea and lemma-like structures. One floret consists of one pistil and three stamens. Another floret consists of a calus-like structure (arrowhead) and three stamens; $(\mathrm{H})$ The spikelet has three pistils; I, the spikelet has one incomplete floret which consist of one pistil and three stamens; (J) The spikelet has two incomplete florets and some bulged tissues (arrowhead) between the two florets. 


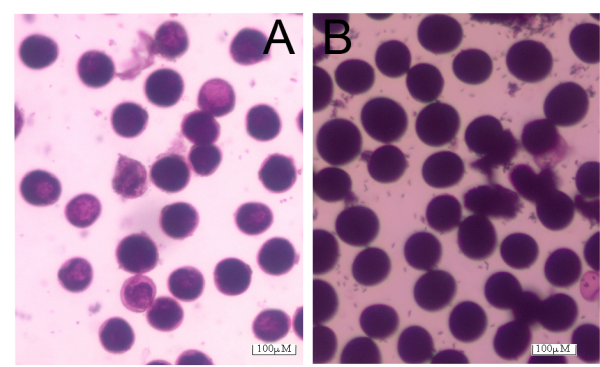

Figure 4. The pollen fertility of srs2 mutant. (A) $\mathrm{I}_{2}$-KI staining of the mutant pollen grains; (B) $\mathrm{I}_{2}-\mathrm{KI}$ staining of wild-type pollen grains.

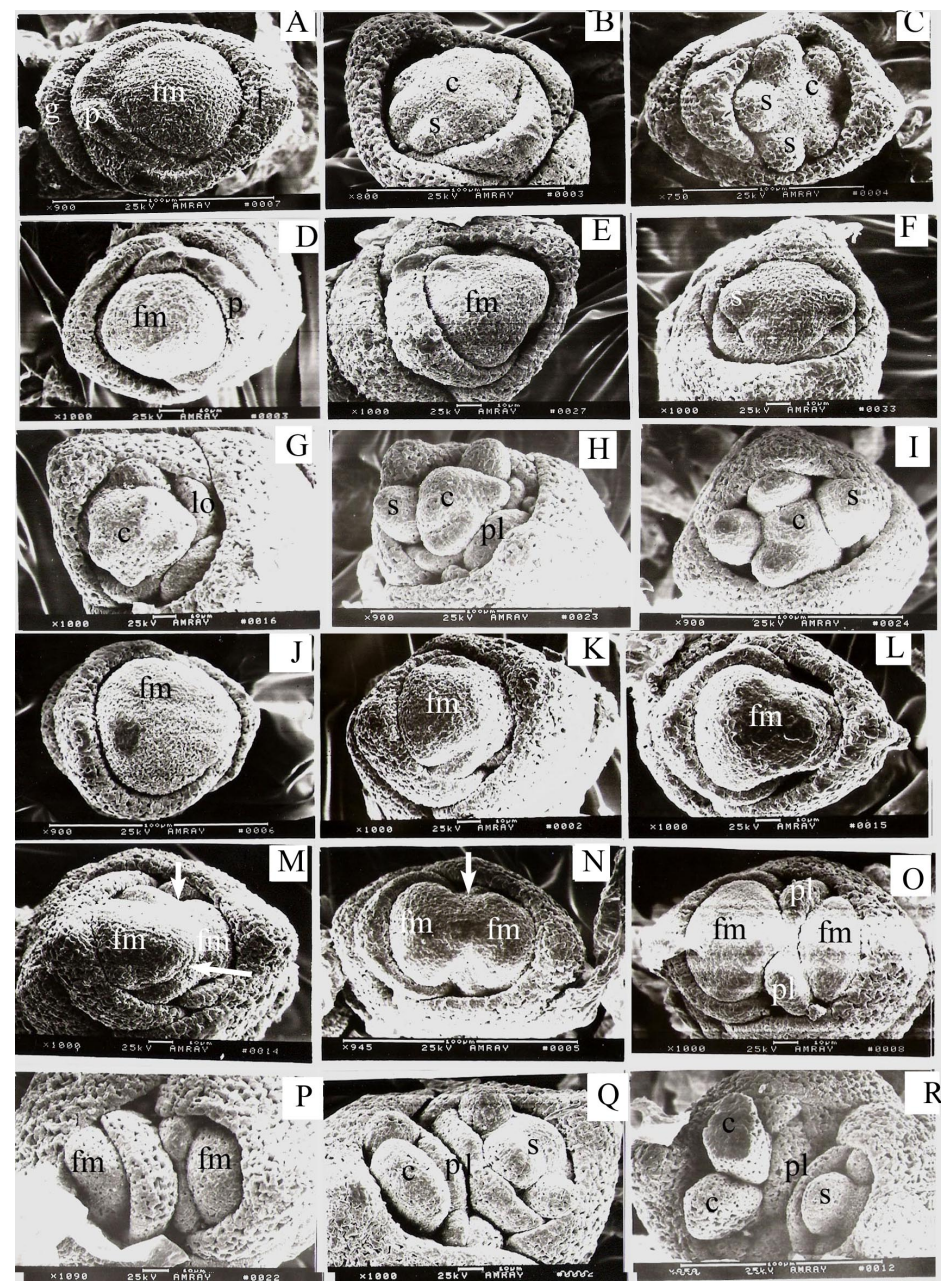

Figure 5. Scanning electron micrographs of floral organ morphogenesis. (A)-(C) A spikelet of the wild type rice GNZ. (A) The wild type floret primordial; (B) Early period of the stamen formation; C, Stamen primordia were formed; (D)-(I) Floral organ morphogenesis in single-floret mutant; (D) Abnormal development of the floral primordia; (E) The floral primordia abnormally developed in a triangle; (F) Formation of the primordia of stamen; $(G)$ Formation of the primordia of lodicule; H, Abnormal development of the lodicule primordial; (I) Development of the primordia of the stamen and carpel; (J)-(R), Floral organ morphogenesis in double-floret mutant. (J) A mutant floral primordia; (K) The mutant floral primordial shrinked from one side; (L) A spindle floral primordial formed in the mutant; (M)-(O) Formation of the two floral primordia and the palea and lemma-like structures as intervals; (P) Another palea and lemma-like structures formed; (Q) Development of the stamen; (R) Formation of the stamen and carpel. Arrows indicat the trace of the shrinking. 
hyperplastic lodicules (Figure 5(G)) close to the lemma were generated around the pistil primordium (Figure 5(I)). The hyperplastic lodicules were abnormally developed and finally formed the palea/lemma-like organs (Figure 5(H)). At this stage, apparent constriction were formed at the center of the floral primordium in the two-floret mutant (Figures 5(M)-(O)), and as a result the floral primordium began to split unequally and subsequently formed two separate asymmetric floral primordia. Furthermore, several palea/lemma-like structures were then generated from the constriction and formed the partition between two florets (Figure 5(P)). Finally, the two separate primordial underwent stamen and pistil primordium differentiation to generate two florets from the same rachilla (Figure 5(R)).

\subsection{Genetic Analysis of the Mutant Gene}

During the heading stage, individual plants in the $F_{1}$ and $F_{2}$ progenies from the crosses between srs2 and other normal rice lines were investigated. In the $4 \mathrm{~F}_{1}$ progenies, all plants exhibited the wild-type phenotype, suggesting that the mutant trait was recessive. In the $4 \mathrm{~F}_{2}$ populations, all the segregation rates of wild type and the mutant plants fit the ratio of 3:1 $\left(\mathrm{X}^{2}<\mathrm{X}^{2} 0.05,1=3.84\right)$; and additionally, in the $2 \mathrm{BC}_{1} \mathrm{~F}_{1}$ populations, the segregation rates fit the ratio of 1:1 (Table 1$)\left(X^{2}<X^{2} 0.05,1=3.84\right.$ ). The data was analyzed Chi-square test [23]. Therefore, the mutant trait was controlled by a single recessive gene, and termed srs2 (Spit rice spikelet 2).

\subsection{Molecular Mapping of the Mutant Gene}

The polymorphisms between srs2 and other rice lines G630, M63 and 202R, respectively, were examined with 512 SSR markers and the most polymorphic population, srs2/202R, was selected for genetic mapping. First, a total of 121 SSR polymorphic markers were selected and used to survey in a small population including the 2 parents, 4 of wild-type $F_{2}$ plants, and 6 of $F_{2}$ mutant plants. The result showed that one SSR marker, RM5886, located on chromosome 3, was obviously associated with the srs2 phenotype (Figure 6(A)). The marker RM5886 was then utilized to survey all 643 mutant plants in the same $F_{2}$ population, and revealed 65 recombinants. Thus, RM5886 was verified to be linked to srs2 on one side with a genetic distance of $5.0 \mathrm{cM}$. Subsequently, other 30 SSR markers, located at the 2000 kbps region around the RM5886 in rice genome, were obtained from GRAMENE and surveyed with the same method. Finally, additional 2 polymorphic markers, RM14649 (located between RM5886 and srs2) and RM1324 (located on the other side of srs2) (Figure 6(A)), were surveyed and revealed 39 and 3 recombinants, respectively, indicating the genetic distance of 3 and 0.23 $\mathrm{cM}$, respectively.

Based on the known rice genomic sequences provided by the TIGR (http://rice.plantbiology.msu.edu/), other 40 new SSRs, InDels, and CAPS markers were then developed according to Zhang et al. (2004) between RM14649 and RM1324. Another 3 polymorphic markers, S31 (located between RM1324 and srs2), S12 (located between RM1324 and srs2), and L75 (located between RM14649 and srs2) (Figure 6(A), Table 2) were then discovered and revealed 1,2 , and 26 recombinants, respectively, indicating a genetic distance of $0.08,0.16$ and 2cM, respectively. Based on the segregation data, a local linkage map around srs2 was constructed (Figure 6(B)), showing that srs2 was located between the molecular markers S31 and L75, at a distance of 0.08 and 2 cM on chromosome 3, respectively.

Table 1. Segregation of the mutation in different population.

\begin{tabular}{|c|c|c|c|c|c|}
\hline Population & Total Individuals & $\begin{array}{l}\text { Wild-type } \\
\text { Individuals }\end{array}$ & $\begin{array}{c}\text { Mutant } \\
\text { Individuals }\end{array}$ & $\begin{array}{l}\text { Expected } \\
\text { Value }\end{array}$ & $\begin{array}{c}\text { Chi-Square } \\
\text { Value }\end{array}$ \\
\hline srs2 $\times 9311$ & 186 & 142 & 44 & $3: 1$ & 0.12 \\
\hline srs2 $\times$ G630 & 179 & 139 & 40 & $3: 1$ & 0.54 \\
\hline srs2 $\times$ M63 & 240 & 183 & 57 & $3: 1$ & 0.14 \\
\hline $\operatorname{srs} 2 \times \mathrm{GNZ}$ & 227 & 172 & 55 & $3: 1$ & 0.04 \\
\hline$s r s 2 \times(\mathrm{GNZ} \times \operatorname{srs} 2) \mathrm{BC} 1 \mathrm{~F} 1$ & 49 & 29 & 20 & $1: 1$ & 1.31 \\
\hline $\operatorname{srs} 2 \times(\operatorname{srs} 2 \times 9311) \mathrm{BC} 1 \mathrm{~F} 1$ & 36 & 22 & 14 & $1: 1$ & 1.36 \\
\hline
\end{tabular}

Note: $X^{2}=0.05,1=3.84$. 


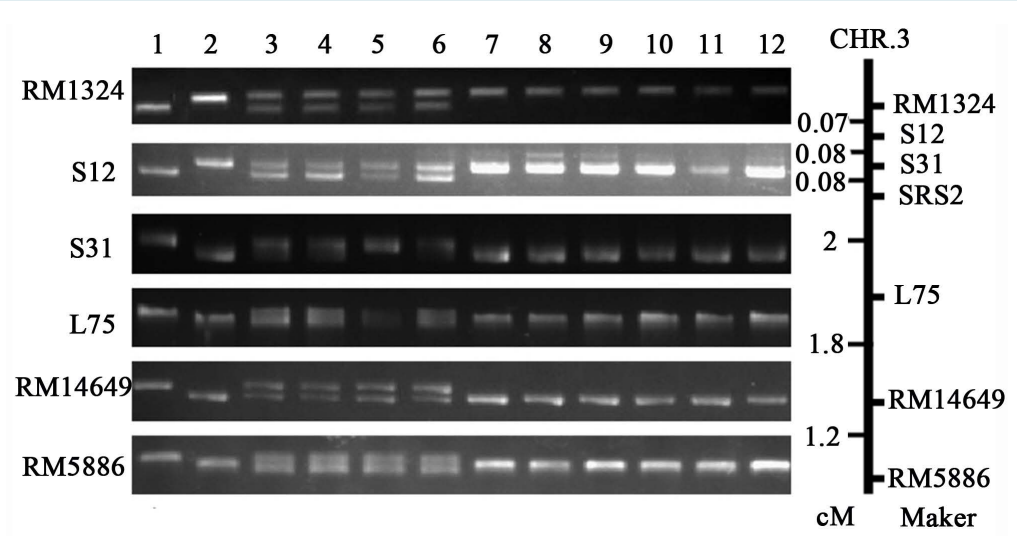

(A)

(B)

Figure 6. Molecular mapping of the mutant gene. (A) Segregation patterns of the SSR markers in the small population; $1,202 \mathrm{R} ; 2$, srs2; 3-6, $\mathrm{F}_{2}$ wild-type plants; $7-12, \mathrm{~F}_{2}$ mutant plants; (B) The location of SRS2gene in the molecular linkage map on rice chromosome 3 . The genetic distance (cM) between two molecular markers is shown on the left.

Table 2. Newly developed markers used in mapping.

\begin{tabular}{rrrccc}
\hline Marker & Type & Forward sequence (5'-3') & Reverse sequence (5'-3') & $\begin{array}{c}\text { Anneal } \\
\text { Temperature }\left({ }^{\circ} \text { C) }\right.\end{array}$ & $\begin{array}{c}\text { Expected PCR } \\
\text { Product Size (bp) }\end{array}$ \\
\hline S12 & SSRs & CAACTCATATAACAGCAAGATCAGC & AAAGCGAAAGTCAACAGG & 49.6 & 184 \\
S31 & SSRs & TACTTCTACCCAAGCAGG & CTCTCAAACGCTTGCCAT & 49 & 231 \\
L75 & InDels & ATCAGCCCCAAATCAAACCC & CCTCCCTCACTTCCCCTTCC & 51 & 132 \\
\hline
\end{tabular}

\section{Discussion}

In the present study, srs2 was proven to have split spikelet, abnormal stamens, palea/lemma-like lodicules, twin floret from the same rachilla, a decrease in stamen number, an increase in pistil number as well as low seed-setting-rate. The results of SEM indicated that the androecium and gynoecia developed abnormally from the early stage of floral primordium differentiation. By applying a chromosome-walking strategy, srs2 was finally mapped to rice chromosome 3 between S31 and L75.

\subsection{Srs2 Is a New Gene Involving Rice Floral Organ Development}

Bai et al. [7] reported a floral mutant, SRS, with the similar phenotype with srs2. SRS has long and soft split paleas/lemmas, an additional floret at the base of the lemma, and 2 palea/lemma-like lodicules. The ultimate difference between the two mutants was that the location and the appearance of the pistils and stamens were normal in SRS, while these organs were seriously affected and displayed malformation in srs2. Srs1 gene was previously mapped between RG450 and RG266 (physically located from 3,476,386 bp to 5,418,449 bp) on rice chromosome 3 [31]. However, srs2 was mapped to another region flanked by the makers S31 and L75 (physically located from $6,027,745$ bp to 7,053,941 bp) on chromosome 3. Thus, it could be concluded that srs 2 was not allelic to srs1, though the phenotype of the two mutants were very close. Another similar mutant to srs2 was the lhs1 mutant, which has been reported previously with a phenotype of leaf-like transformation of paleas and lemmas, and be controlled by a single recessive gene [15]. In the weak phenotype of the Ihs1 mutant, the spikelet consists of leafy palea and lemma, two pairs of palea- and lemma-like structures, fewer stamens, and more pistils. In plants with the strong phenotype, the lhs1 mutation results in generation of new flowers within the spikelet. Jeon et al. [32] subsequently proved that lhs1 is a homeotic mutation in a rice MADS box gene affecting rice flower development. The phenotype of the lhs1 mutant was attributable to the alterations of OsMADS1, and complementation experiment showed that an 11.9-kb genomic DNA fragment containing the wild-type OsMADS1 gene rescued the lhs1 mutant phenotype. For the OsMADS1 was located from 6,031,865 bp to $6,040,484$ bp on chromosome 3, within the srs2 mapping region, the full length genomic DNA of OsMADS1 of 
the srs2 mutant was cloned and sequenced to investigate whether srs2 stemmed from OsMADS1 mutation. Sequence comparison of Nipponbare (a wild-type Japonica rice variety which genomic sequence was publicly available) and srs2 revealed no nucleotide changes in the OsMADS1 gene locus (data not shown). Therefore, it is concluded that the srs2 phenotype was not attributable to the alterations of OsMADS1 and that SRS2 was a new gene controlling split spikelet. According to the rice genomic annotation of TIGR

(http://rice.plantbiology.msu.edu/), there were no other MADS box genes in the SRS2 mapping region. An interesting question that arises from this information is that the SRS2 might be a novel type floral development controlling gene. Xiao et al. [33] reported a single $\mathrm{C}_{2} \mathrm{H}_{2}$ zinc finger protein, sl1, a closely related gene of Arabidopsis JAG, regulates floral organ identity in rice. Sun et al. [34] has also demonstrated that rice JMJ706 encodes a heterochromatin-associated H3K9 demethylase involved in the regulation of flower development in rice, indicating a novel mechanism of epigenetic modification also works in floral organ identity.

\subsection{Srs2 Might Be Involved in Various Stages of Rice Floral Organ Development}

According to the ABC model put forward from the studies in Arabidopsis and Antirrhinum, sepals are specified by the A class genes, and petals by a combination of the class A and B genes. Stamens are specified by class B and $\mathrm{C}$ genes together, and carpels are specified by the class $\mathrm{C}$ gene alone. The functions of the class $\mathrm{A}$ and class $\mathrm{C}$ genes are mutually antagonistic such that loss of the class A gene results in $\mathrm{C}$ activity in all four whorls, and vice versa [35]. Rice is a member of the grass family, which is one of the large clade in monocots. The inflorescences in the grass family are distinct to those in dicots. The unique units of rice inflorescence are spikelet, which consisted of one lemma, one palea, two lodicules, six stamens, and one carpel. The flower lacks obvious petals and sepals but instead has distinct structures called the palea and the lemma. In addition, lodicules are small and fleshy organs located at the base of the ovary, and are considered to be homologous to the floral petals of dicot plants. The floral primordium of srs2 mutant might be differentiated into various floral organs irregularly. There were many abnormal lodicules, stamens, pollen grains and pistils in the mutant spikelet, which indicated that the srs2 gene played various roles in the floral organ determination through all the stages of rice floral organ development. Besides, in the srs2 mutant, two separate asymmetric floral primordial were usually formed from the floral primordium and finally generated two florets in the same rachilla. It indicated that SRS2 gene may also play a vital role in repressing the expression of the floral primordium identity gene after the floral primordium was formed. Consistent with the OSMADS1 gene, the SRS2 gene also affected the development of lodicules. There were two reasons leading to the abnormal development of lodicules. First, lacking of srs2 gene resulted in the down-regulation of genes related to lodicule development. Second, these abnormal lodicules were incomplete substitutions of paleas/lemmas (whorl 1) in lodicules (whorl 2) [32]. The characteristics of the srs2 mutants also suggested that the SRS2 gene may functionally interact with the A class gene in rice.

\section{References}

[1] Coen, E.S. and Meyerowitz, E.M. (1991) The War of the Whorls: Genetic Interactions Controlling Flower Development. Nature, 353, 31-37. http://dx.doi.org/10.1038/353031a0

[2] Colombo, L., Franken, J., Koetje, E., van Went, J., Dons, H.J.M., Angenent, G.C. and van Tunen, A.J. (1995) The Petunia MADS-Box Gene FBP11 Determines Ovule Identity. Plant Cell, 7, 1859-1868. http://dx.doi.org/10.1105/tpc.7.11.1859

[3] Pelaz, S., Ditta, G.S., Baumann, E., Wisman, E. and Yanofsky, M.F. (2000) B and C Floral Organ Identity Functions Require SEPALLATA MADS-Box Genes. Nature, 405, 200-203. http://dx.doi.org/10.1038/35012103

[4] Pelaz, S., Gustafson-Brown, C., Kohalmi, S.E., Crosby, W.L. and Yanofsky, M.F. (2001) APETALA1 and SEPALLATA3 Interact to Promote Flower Development. Plant Journal, 26, 385-394. http://dx.doi.org/10.1046/j.1365-313x.2001.2641042.x

[5] Honma, T. and Goto, K. (2001) Complexes of MADS-Box Proteins Are Sufficient to Convert Leaves into Floral Organs. Nature, 409, 525-529. http://dx.doi.org/10.1038/35054083

[6] Theissen, G. (2001) Development of Floral Organ Identity: Stories from the MADS House. Current Opinion in Plant Biology, 4, 75-85. http://dx.doi.org/10.1016/S1369-5266(00)00139-4

[7] Bai, S.L., Liu, Y.S., Sun, J.S. and Xie, R. (2000) Identification of the Mutant of Split Rice Spikelet (SRS). Acta Botanica Sinica, 42, 122-125.

[8] Liang, K.J., Wang, J.L., Yao, X.L. and Lin, J., et al. (2007) Gentic Analysis and Morphogenesis of Floral Mutant Split 
Rice Glume. Journal of Fujian Agriculture and Forestry University (Natural Science Edition), 36, 225-229.

[9] Zhang, Q.F., Xu, J.D., Li, Y., Xu, P.Z., Zhang, H.Y. and Wu, X.J. (2007) Morphological, Anatomical and Genetic Analysis for a Rice Mutant with Abnormal Hull. Journal of Genetics and Genomics, 34, 519-526. http://dx.doi.org/10.1016/S1673-8527(07)60057-5

[10] Luo, Q., Zhou, K.D. and Zhao, X.F., et al. (2005) Identification and Fine Mapping of a Mutant Gene for Palealess Spikelet in Rice. Planta, 221, 222-230. http://dx.doi.org/10.1007/s00425-004-1438-8

[11] Nagasawa, N., Miyoshi, M., Sano, Y., et al. (2003) SUPERWOMAN1 and DROOPING LEA F Genes Control Floral Organ Identity in Rice. Development, 130, 705-718. http://dx.doi.org/10.1242/dev.00294

[12] Mackill, D.J., Pinson, S.R.M. and Rutger, J.N. (1991) Frizzy Panicle, an EMS-Induced Mutant in Japonica Cultivar M-201. Rice Genetics Newsletter, 9, 100-102.

[13] Zhang, X., Li, S.G., Wang, Y. and Wu, X.J. (2004) Morphogenesis, Anatomical Observation and Genetic Analysis of a Long Hull Floral Organ Mutant in Rice. Acta Botanica Sinica, 46, 451-456.

[14] Pan, C.H., Li, A.H., Wu, R., Zhang, Y.F., Tang, W., Wu, C.Y. and Zhang, Q.F. (2006) Morphogenesis, Anatomical Observation and Primary Genetic Analysis of a Multi-Glume Floral Organ Mutant in Rice. Rice Science, 13, $227-233$.

[15] Khush, G.S. and Librojo, A.L. (1985) Nakedseed Rice (NSR) Is Allelic to op and Lhs. Rice Genetics Newsletter, $2,71$.

[16] Matsuoka, M., Ichikawa, H., Saito, A., Tada, Y., Fujimura, T. and Kano-Murakami, Y. (1993) Expression of a Rice Homeobox Gene Causes Altered Morphology of Transgenic Plants. Plant Cell, 5, 1039-1048. http://dx.doi.org/10.1105/tpc.5.9.1039

[17] Prasad, K., Sriram, P., Kumar, C.S., Kushalappa, K. and Vijayraghavan, U. (2001) Ectopic Expression of Rice OsMADS1 Reveals a Role in Specifying the Lemma and Palea, Grass Floral Organs Analogous to Sepals. Development Genes and Evolution, 211, 281-290. http://dx.doi.org/10.1007/s004270100153

[18] Moon, Y.H., Jung, J.Y., Kang, H.G. and An, G. (1999) Identification of a Rice APETALA3 Homologue by Yeast Two Hybrid Screening. Plant Molecular Biology, 40, 167-177. http://dx.doi.org/10.1023/A:1026429922616

[19] Kang, H.G., Jeon, J.S., Lee, S. and An, G. (1998) Identification of Class B and Class C Floral Organ Identity Genes from Rice Plants. Plant Molecular Biology, 38, 1021-1029. http://dx.doi.org/10.1023/A:1006051911291

[20] Lopez-Dee, Z.P., Wittich, P., Enrico Pè, M., Rigola, D., Del Buono, I., Sari-Gorla, M., Kater, M.M. and Colombo, L. (1999) OsMADS13, a Novel Rice MADS-Box Gene Expressed during Ovule Development. Genes \& Development, 25, 237-244. http://dx.doi.org/10.1002/(SICI)1520-6408(1999)25:3<237::AID-DVG6>3.0.CO;2-L

[21] Greco, R., Stagi, L., Colombo, L., Angenent, G.C. and Sari-Gorla, M. (1997) E MADS Box Genes Expressed in Developing Inflorescences of Rice and Sorghum. Molecular Genetics and Genomics, 253, 615-623. http://dx.doi.org/10.1007/s004380050364

[22] Chung, Y.Y., Kim, S.R., Finkel, D., Yanofsky, M.F. and An, G. (1994) Early Flowering and Reduced Apical Dominance Result from Ectopic Expression of a Rice MADS Box Gene. Plant Molecular Biology, 26, 657-665. http://dx.doi.org/10.1007/BF00013751

[23] Zuo, L., Li, S.C., Chu, M.G., Wang, S.Q., Deng, Q.M., Ding, L., Zhang, J., Wen, Y., Zheng, A.P. and Li, P. (2008) Phenotypic Characterization, Genetic Analysis and Molecular Mapping of a New Mutant Gene for Male Sterility in Rice. Genome, 51, 303-308. http://dx.doi.org/10.1139/G08-009

[24] Zhu, Y.G. and Yang, D.C. (1992) Studies and Utilization on Photoperion-Sensitive Genetic Male Sterile Rice. Wuhan University Press, Wuhan, 276.

[25] Li, S.C., Yin, D.S., Zhou, H.Q., Wang, S.Q., Deng, Q.M., Tang, Y.H., Wu, F.Q. and Li, P. (2006) Introduction of the PPF1 Gene into Rice (Oryza sativa L.) Results in Delayed Leaf-Senescence. Euphytica, 153, 257-265. http://dx.doi.org/10.1007/s10681-006-9261-x

[26] Feng, M., Fu, D.Z., Liang, H.X. and Lu, A.M. (1995) Floral Morphogenesis of Aquilegia L. (Ranunculaceae). Acta Botanica Sinica, 37, 791-794.

[27] Mizukami, Y. and Ma, H. (1992) Ectopic Expression of the Floral Homeotic Gene AGAMOUS in Transgenic Arabidopsis Plants Alters Floral Organ Identity. Cell, 71, 119-131. http://dx.doi.org/10.1016/0092-8674(92)90271-D

[28] Wang, G.L. and Fang, H.J. (1998) Principle and Technology of Plant Genetic Engineering. The Science Press, Beijing.

[29] Zhang, X.Y. and Kao, Y.L. (2004) To Design PCR Primers with Oligo 6 and Primer Premier 5. Chinese Journal of Bioinformatics, 2, 1-8.

[30] Lander, E.S., Green, P. and Abrahamson, J. (1987) Mapmarker: An Interactive Computer for Constructing Primary Genetics Linkage Maps of Experimental and Natural Populations. Genetics, 1, 174-181.

[31] Bai, S.L., Liu, Y.S., Sun, J.S. and Zhu, L.H. (2000) Molecular Mapping of Split Rice Spikelet Mutant Srs-1 and Analysis of Its Homeotic Function in Rice. Science in China (Series C), 43, 369-375. 
http://dx.doi.org/10.1007/BF02879301

[32] Jeon, J., Jang, S., Lee, S., Nam, J., Kim, C., Lee, S., et al. (2000) Leafy Hull Sterile1 Is a Homeotic Mutation in a Rice MADS Box Gene Affecting Rice Flower Development. The Plant Cell, 12, 871-884. http://dx.doi.org/10.1105/tpc.12.6.871

[33] Xiao, H., Tang, J.F., Li, Y.F., Wang, W.M., Li, X.B., Jin, L., Xie, R., Luo, H.F., Zhao, X.F., Meng, Z., He, G.H. and Zhu, L.H. (2009) STAMENLESS 1, Encoding a Single C2H2 Zinc Finger Protein, Regulates Floral Organ Identity in Rice. The Plant Journal, 59, 789-801. http://dx.doi.org/10.1111/j.1365-313X.2009.03913.x

[34] Sun, Q.W. and Zhou, D.X. (2008) Rice jmjC Domain-Containing Gene JMJ706 Encodes H3K9 Demethylase Required for Floral Organ Development. Proceedings of the National Academy of Sciences of the United States of America, 105, 13679-13684. http://dx.doi.org/10.1073/pnas.0805901105

[35] Bommert, P., Namiko, S., Jackson, D. and Hirano, H. (2005) Genetics and Evolution of Inflorescence and Flower Development in Grasses. Plant and Cell Physiology, 46, 69-78. http://dx.doi.org/10.1093/pcp/pci504 